See discussions, stats, and author profiles for this publication at: https://www.researchgate.net/publication/322907427

\title{
Predicting Alliance for Depressed and Suicidal Adolescents: The Role of Perceived Attachment to Mothers
}

Article · February 2018

DOI: 10.1080/23794925.2018.1423893

CITATIONS

2

5 authors, including:

Maliha Ibrahim

Young Lives

6 PUBLICATIONS 2 CITATIONS

SEE PROFILE

Guy Diamond

University of Pennsylvania

75 PUBLICATIONS 2,476 CITATIONS

SEE PROFILE
READS

94

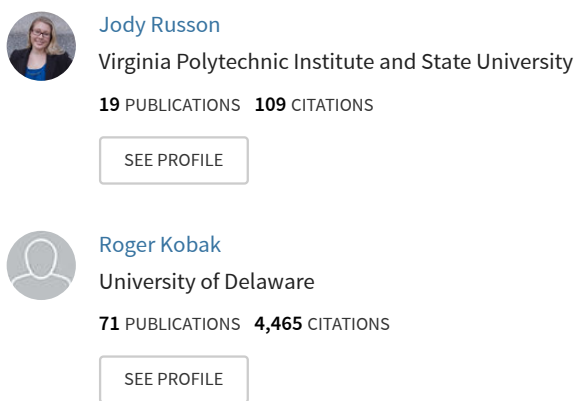

Some of the authors of this publication are also working on these related projects:

A Process Evaluation of A Substance Use Program for Pregnant Women: Lessons Learned from the Field View project

Life Skills Assessment for early adolescents View project 


\begin{abstract}
Background. Although therapeutic alliance is a robust predictor of treatment outcomes in child and adolescent psychotherapy, less is known about relational factors, such as youth's attachment, to mothers and fathers. The current study investigated anxious or avoidant attachment to mothers or fathers as predictors of early formation of the therapeutic alliance in a high-risk sample of depressed and suicidal adolescents.

Methods. Changes in adolescents' alliance ratings between the first and fourth treatment sessions was examined in a comparative efficacy trial $(\mathrm{N}=115)$ of Attachment Based Family Therapy and Family Enhanced Non-Directive Supportive Therapy for suicidal and depressed adolescents. Multilevel regression analysis accounted for nested data by therapist and treatment condition. Results. After accounting for significant random effects in our multilevel model associated with therapist to treatment condition, results revealed a significant effect of perceived insecurity to mothers leading to lower levels of therapeutic alliance at session four $(\beta=-0.49, p<.05)$. Discussion. The quality of adolescents' attachments to parents may play an important role in adolescents’ ability to form strong working relationships with a therapist. Findings suggested that adolescents with avoidant attachment styles may be more difficult to engage in treatment and could benefit from specific interventions focused on alliance-building.
\end{abstract} Key words: alliance, family therapy, adolescents, attachment insecurity 


\section{Background}

Therapeutic alliance predicts $12 \%$ of treatment outcomes, above and beyond therapeutic techniques (Bordin, 1979; Horvath, Del Re, Fluckiger \& Symond, 2011; Lambert \& Barley, 2001; Martin, Garske \& Davis, 2000; Wampold, 2001). These findings generalize across clinical populations, treatment modalities, assessment time points, and/or types of measurement (Barber, Connolly, Crits-Christoph, Gladis, \& Siqueland, 2000; Horvath, 2000; Lambert \& Barley, 2001; Safran \& Muran, 2000; Shirk, Gudmundsun, Kaplinkski, \& McMakin, 2008). Even so, research on therapeutic alliance for adolescent populations is limited (Baylis, Collins, \& Coleman, 2011; DiGiuseppe, Linscott, \& Jilton, 1996, Green, 2006; Hawley \& Garland, 2008; Shirk, Karver, \& Brown, 2011). A fuller understanding of the factors that contribute to adolescent therapeutic alliance could reduce dropout rates and improve treatment response (De Haan, Boon, de Jong, Hoeve, \& Vermeiren, 2013; Levin, Henderson, \& Ehrenreich-May, 2012). Furthermore, this line of research could aid the development of alliance-building interventions that improve treatment retention and outcome (Castro-Blanco \& Karver, 2010; Crits-Christoph et al., 2006; Diamond, Liddle, Hogue, \& Dakof, 1999; Eliot, 2009; Wintersteen, Mensinger, \& Diamond, 2005).

Most research on factors that influence alliance formation with adolescent clients has focused on demographics or symptom severity. Relational factors have received less attention (Constantino, Arnow, Blasey, \& Agras, 2005; Sexton, Littauer, Sexton, \& Tommeras, 2005; Strauss et al., 2006). Some research has investigated family factors (e.g., communication, family structure, and family functioning) as predictors of alliance (Karver, Handlesman, Fields \& Bickman, 2006; Galdiolo \& Roskam, 2016; Spoth, Redmond, Hockaday, \& Shin, 1996; Thompson, Bender, Lantry, \& Flynn, 2007). Unfortunately, these studies have yielded inconsistent findings (Diener \& Monroe, 2011; Duchesne \& Ratelle, 2014) and have been largely 
limited to global measures of family functioning that do not examine specific relationships with adult caregivers. Adolescents’ views of their relationships with both mother and father figures may be one domain worthy of further investigation.

\section{Attachment}

Attachment theory may illuminate how adolescents’ relationships with their adult caregivers might influence the formation of the therapeutic alliance. The attachment framework posits that, when adolescents perceive their caregivers as available and responsive, they are more likely to feel secure and perceive themselves as worthy of love and protection (Kobak, Zajac and Madsen, 2016). Over time, youth maintain these expectancies for caregiver availability as working models or schemas that inform their views of self and others (Bowlby, 1969; 1973; Bretherton \& Munholland, 2008). Positive expectancies for caregiver availability organize secure schemas for self and other, while negative expectancies organize insecure, avoidant, or ambivalent schemas (e.g., "My father is consistently unresponsive when I need him; therefore, my needs are not important and, by extension, I am not important enough to be cared for.”) (Kobak \& Zajac. 2011). That is, youth respond to others as if the relational schema relationships were true (e.g., "I avoid other people because they could not possibly care for someone like me.”). This map for experiencing self and others is not consciously developed (Maier, Bernier, Pekrun, Zimmermann, \& Grossmann, 2004). Adolescents that maintain negative expectancies for others are likely to develop avoidant or ambivalent attachment styles (Mikulencer, \& Shave \& Berant, 2013). Informed by their internal working model, adolescents interact with important others in a way that is consistent with their expectations (Shomaker \& Furman, 2009).

Adolescents struggling with depression and suicide are often a part of family systems experiencing multiple stressors (e.g., family conflict, multigenerational abandonment, parental 
rejection, systemic trauma, history of suicidality, or other mental health issues). Consequently, these multiple stressors may contribute to adolescents’ negative expectations for availability and responsiveness from their adult caregivers (Allen, Hauser, \& Borman-Spurrell, 1996; Bowlby, 1969, 1988; Clark \& Symons, 2009; Waters, Merrick, Treboux, Crowell, \& Albersheim, 2000). Yet, even within highly stressed families, adolescents vary in the extent to which their expectancies generalize from parents to other adult caregivers such as teachers or therapists. For instance, some adolescents may develop an avoidant style with parents and then look to other adults (e.g., therapist) to form a more secure attachment, while others may develop anxious styles; longing for, but not trusting their relationship with a therapist (DeWinter, Bosmans, \& Salemink, 2017). Accordingly, it is important to consider the nuances of the relational patterns adolescents develop with specific caregivers and adult figures.

Research with adults suggests that the quality of attachment to mothers and fathers may influence the therapeutic relationship. Attachment security to fathers has been associated with a sense of self-efficacy and competence in therapeutic tasks, while attachment security to mothers has been associated with mutual warmth and collaboration with a therapist (Mikulincer et al., 2013). Other studies have found differential contributions of mother and father attachment to the therapeutic alliance. Duchesne and Ratelle, (2014) found that attachment security to mothers vs. fathers contributed to different trajectories of depression symptoms; for example, attachment insecurity with mothers predicted increased levels of depression over time. Other studies have suggested that attachment insecurity to mothers was associated with problems in early therapeutic alliance, while attachment insecurity to fathers is associated with higher alliance ratings (Johnson, Ketring, Rohacs \& Brewer, 2006; Tereno, Soares, Martins, Celani, \& Sampaio, 2008). 
The associations between attachment and therapeutic alliance have been explored in two studies with adolescent samples. Adolescents from a non-specific clinical population, perceived attachment insecurity to parents predicted lower alliance scores, while those who felt greater trust in their parents had higher levels of alliance with the therapist (Johnson et al., 2006). In a more recent study with substance dependent adolescents, Zack and colleagues (2015) examined adolescent-caregiver attachment as a moderator of the association between therapeutic alliance and outcome (Zack et al., 2015). Among youth who reported more insecure attachment with caregivers, the alliance outcome association was strongest (Zack et al., 2015). The findings from these two studies suggest that more research is needed on the role of adolescent's perceived attachment to parents and adolescents' ability or willingness to form an alliance with a therapist.

\section{Client, Therapist, and Treatment Factors}

Studies of the adolescents' therapeutic alliance could benefit by accounting for client demographics and psychopathology as well as therapist factors and treatment condition. One study found that formation of the therapeutic alliance was facilitated when therapist and clients' gender was matched; yet in the same sample, racial matching between therapist and client predicted treatment retention, but not alliance (Wintersteen et al., 2005). Socioeconomic factors may also contribute to the strength of the therapeutic relationship with adolescents from lower income household reporting lower levels of alliance (Beck, Friedlander, \& Escudero, 2006; Hawks, 2015). Studies of adult clients have explored whether type or severity of disorder influences the formation of the therapeutic alliance (Bachelor, Meunier, Laverdiere, \& Gamache, 2010; Sexton et al., 2005). In adults, a variety of disorders (depression, suicidal ideation, psychosis and substance abuse have been associated with difficulties forming a therapeutic alliance (Barrowclough, Meier, Beardmore, \& Emsley, 2010;Kazdin, 2005; Martin et al.,2000; 
Shirk et al.,2008). Unfortunately, studies of adolescents have been limited to eating disorders or externalizing disorders in which symptom severity has been associated poorer levels of alliance (Constantino et al., 2005; Green, 2006).

Treatment type and modality have rarely been investigated in adolescent and child studies (Martin et al., 2000; Shirk et al., 2011). Studies with adults have reported better therapeutic alliance in structured approaches to treating depression such as cognitive therapy (Arnow \& Steidtmann, 2014). Other studies have focused on treatment modality such as individual, group, or family therapy. These studies suggest that clients participating in individual therapy reported the highest therapeutic alliance scores (Lindgren, Barber, \& Standahl, 2008; McLeod, 2011).

\section{Present Study}

The purpose of this study was to extend prior research on caregiver-adolescent attachment and the formation of the therapeutic alliance, as applied to a high risk population with acute depressive symptoms and suicidal behavior. We also explored the differential impact of attachment avoidance and attachment anxiety for both fathers and mothers while controlling for demographics and symptom severity. These research aims were explored in the context of two treatments: 1) Attachment-Based Family Therapy (ABFT); and 2) Family Enhanced NonDirective Supportive Therapy (FE-NST). Multi-level modelling accounted for the nested nature of the data, controlling for random effects of therapist and treatment type on therapeutic alliance.

\section{Method}

\section{Participants}

The participants included 115 adolescents aged 13 to $18(M=14.96, S D=1.68)$ who participated in an NIMH-funded randomized control trial examining the efficacy of ABFT compared to FE-NST. Adolescent participants who dropped out of the study $(\mathrm{N}=14)$ were not 
included. Participants largely self-identified as female (82.9\%), a mean age of 14.96 (SD = 1.66) and a little over half self-identified racially as Black/African American $(55.8 \%, \mathrm{n}=72)$, and 15.5\% $(\mathrm{n}=20)$ as Hispanic in their ethnicity. Based on the Diagnostic Interview Schedule for Children (DISC-IV), $46.1 \%$ of the participants met criteria for a mood disorder and $36.3 \%$ for an anxiety disorder. Almost half of the participants (42.2\%) had made a suicide attempt during their lifetime, and 57.5\% reported that they had engaged in non-suicidal self-injury. In addition, $19.8 \%$ of participants reported a history of sexual abuse, and $19.1 \%$ a history of physical abuse. Study participants were recruited from primary care centers, emergency departments, outpatient facilities, inpatient hospitals, schools, churches, and the general community. The Institutional Review Boards at Children's Hospital of Philadelphia, Drexel University, and the City of Philadelphia approved the study protocol. The study was monitored quarterly by a data safety and monitoring board. All participants provided written informed consent.

In order to be eligible for study participation, the participant had to present with clinical levels of suicidal ideation (SIQ-JR > 31; Reynolds \& Mazza, 1999) and moderate levels of depression (BDI-II > 20; Beck, Steer, \& Brown, 1996) at two consecutive, pre-treatment assessment time points. At least one primary caregiver was required to participate in treatment and assessments during both study conditions. . The definition of primary caregiver was broadly defined. A primary caregiver was an adult who the youth identified as having a prolonged and consistent supportive role in the adolescent's life. Other family members were included when clinically indicated. When completing self-report measures, the adolescent participants decide who would be identified as their "mother or mother-like figure" and "father or father-like figure.” In a few cases, these mother figures were not necessarily the caregiver who participated 
in the clinical treatment. In many more of the cases from single caregiver families, father figures were not the caregiver who participated in treatment.

Exclusion criteria included: a) being an imminent risk of harm to self or others who could not be safely treated in an outpatient program; b) having a history of psychosis; and c) Having severe cognitive impairment based on educational records, parent report, and/or clinical impression. The study treatment sessions were conducted in English; therefore, all families needed to be fluent in the English language in order to participate. Participants who began medication within three weeks of the pre-treatment assessment were ineligible for participation until a three week time period had passed.

\section{Therapists}

There were 17 different therapists who served on the study; 11 therapists delivered both therapy types (a cross over design) while six therapists delivered only FE-NST. Therapist demographic characteristics included: age range of 25 to 58; 4 men and 13 women; all at least Master's level educated; and racial identification of included White (52\%, $N=9)$, AfricanAmerican (24\%, $N=4)$, Biracial $(12 \%, N=2)$ and Other $(12 \%, N=2)$. The study therapists had prior training in modalities like cognitive-behavior therapy, solution-focused therapy, family therapy and psychodynamic therapy. In preparation for their participation for the study, all cross over therapists were provided treatment specific training in ABFT and FE-NST.

\section{Treatments}

Attachment-Based Family Therapy. ABFT is a 16-week treatment for adolescents aged 12 to 18 (Diamond, Diamond, \& Levy, 2014). ABFT is informed by attachment theory and suggests that depression and suicide can be precipitated, exacerbated, or buffered by the quality of family relationships. Family processes such as family conflict, detachment, harsh criticism, or 
more vociferous traumas (e.g., abandonment, neglect, and abuse) can rupture family security. These ruptures can, in turn, deny the adolescent a protective developmental context. ABFT aims to strengthen or repair parent-adolescent attachment bonds and family communication. This allows parents to become resource to help their adolescent cope with stress, experience competency, and explore autonomy. The initial stage of the treatment, Task I involved both adolescents and parents. Task II and III were individually conducted with adolescents and parents alone and Task IV and V were conducted conjointly with parents and adolescents.

Family Enhanced Non-directive Supportive Therapy. FE-NST is as modification of the therapeutic approach described in the Supportive Relationship Treatment Manual (Brent \& Kolko, 1991). FE-NST is also a 16 week treatment focused on developing a supportive relationship between adolescent client and therapist. The therapist engages with the client by attending, listening, providing empathy, and demonstrating unconditional positive regard (Rogers, 1977). Sessions are unstructured and focus on the issues raised by the client. Parents participate in the first session with the adolescent. Next, they have four separate parents alone education sessions for 60 minutes each where they received psycho-education on depression, suicidal risk management, advocacy, and problem-solving. In FE-NST, therapists help the parent develop support systems for the adolescent. The parent educator was not the adolescent's therapist, but another member of the therapeutic team.

\section{Measures}

Attachment to parents. The Experiences in Close Relationships-Relationship Structures Questionnaire (ECR-RS; Fraley, Hefferman, Vicary, \& Brumbaugh, 2011) assesses the perceived anxious or avoidant attachment styles of adolescents with their mother (or motherlike figure) and father (or father-like figure). Each relationship is rated on a series of 9 questions 
using a 7-point Likert scale ranging from 1 (Strongly disagree) to 7 (Strongly agree). Two subscales for each parent are calculated: attachment-related avoidance and attachment-related anxiety. These subscales have exhibited good internal consistency, with Cronbach's alpha, $\alpha=$ .80 and .78 for attachment anxiety and $\alpha=0.80$ and 0.78 for attachment avoidance (Fraley et al., 2011). They have also maintained good external validity and retest reliability. In our study sample, the measure displayed good internal consistency for both attachment anxiety ( $\alpha=0.84$ and 0.89 for mothers and fathers, respectively) and attachment avoidance $(\alpha=0.85$ and 0.91 , respectively) subscales.

Therapeutic alliance. The Therapeutic Alliance Quality Scale (TAQS) is one of 11 mental health scales on the Peabody Treatment Progress Battery (PTPB; Riemer et al., 2012). The TAQS was chosen as a brief and reliable measure of therapeutic alliance that reduces subject burden in completing post-session measures. TAQS was standardized for clinical trials and delivered to almost 1,000 organizations and is specifically suitable to research conducted with adolescent populations (Riemer et al., 2012). The TAQS has been found to be reliable with a Cronbach's alpha of 0.94 and to have high levels of internal factorial consistency as well as convergent validity with and discriminant validity from other similar measures. The TAQS asks five questions on a Likert scale of 1 to 5 with $1=$ Not at All, and $5=$ Totally $-(1)$ Did the session head in the direction you wanted? (2) Did you understand the things that your counsellor said in the session? (3) Did you and your counselor work on problems together in the session? (4) Did you feel that your counselor would stick with you no matter how you behaved? (5) Did you feel like your counselor understood what it feels like to be you? These questions are designed to measure the bond that the adolescents have with their clinician and their agreement 
on goals and tasks. The TAQS provides a maximum score of 25. The internal consistency in our sample was $\alpha=0.84$.

Suicidal Ideation. The Suicidal Ideation Questionnaire-Junior weekly (SIQ-JR;

Reynolds \& Mazza, 1999) is a 15-item measure that assesses thoughts of suicide over the past week. Participants rate how much they thought about each of the items on a 4 point scale, each selection having an increasing numeric value: a) Never in the past week 0 ; b) About once in the past week 2; c) Couple of times in the past week 4; or d) Almost every day in the past week 6. Items include general thoughts of death (e.g., I thought about people dying) and more specific suicidal plans (e.g., I thought about how I would kill myself). Scores can range from 0 to 90 . In our study sample, the internal consistency was high $(\alpha=.90)$.

Depression. The Beck Depression Inventory-II (BDI-II; Beck et al., 1996) is a widelyused, 21-item self-report instrument designed to assess the severity of depressive symptoms in adults and adolescents. Each of the 21 items is composed of four statements representing increasing increments of depression severity for a specific symptom. The score for each item on the scale ranges from 0-3, with the total ranging from 0-63. The BDI-II has high internal reliability $(\alpha=.91)$ and is highly and positively correlated with other measures of depression. The internal consistency in our study was $\alpha=0.85$.

\section{Procedures}

A multi-gate screening procedure was used with referrals from hospitals and community based mental health agencies. A trained research assistant obtained the first level of information when prospective participants called to find out about the study. The next step was to interview in person. The initial interview included a brief screen for depression and suicidal risk. Next, the research assistant conducted a set of in-person assessments at the intake session. If the patient 
met inclusion criteria at first and second screens, the family was consented and completed the baseline assessment battery. We used Urn randomization to assign participants to 16 weeks of ABFT or FE-NST. Youth were randomized to a treatment condition based on three stratification variables: suicide attempt versus no attempt, level of family conflict, and gender. Each week, a research assistant collected alliance data after every therapy session which was sealed in an envelope to ensure that the therapist would not see the scores.

\section{Data Analysis}

The independent variables in the present study were obtained from baseline data. Our dependent variable, alliance, was measured at session four. Measuring alliance at week three or four is a standard practice in psychotherapy research. By week three or four, the client and therapist have had time to solidify their relationship. If measured earlier, researchers risk assessing clients’ pre-existing impressions of therapy (Fjermesdtad et al., 2012; Krupnick et al., 1996). Alliance scores at session one was used as a control variable in to ensure that our predictors contributed to alliance above and beyond clients’ pre-existing impressions of the therapist or schemas about being in therapy. Additional covariates were included to control for other factors that might impact alliance (Martin et al., 2000, Muehlenkamp, 2006; Shirk et al., 2008; Shirk et al., 2011). These included suicidal ideation, depression, gender, race, age, family income, parental availability in the home, and father's presence in therapy. Family income was based on family income to needs ratio rate. Since many of our adolescents did not live with their fathers, we controlled for their contact time with father. The adolescents reported contact that ranged from daily contact to no contact in the past few years.

Missing data for the target variables were minimal. There were missing data for alliance at session four (missing $n=3$ ), anxious and avoidant attachment to fathers (missing $n=1$ ), and 
father proximity (missing $n=2$ ) variables. The other variables had no missing data. Little’s MCAR test indicated that the missing data was completely at random $\left(\chi^{2}(30)=24.40, p=.75\right.$ > .05); thus it was managed with a maximum likelihood method (Roth, 1994; Schlomer, Bauman, \& Card, 2010). All assumptions for hierarchical linear regression models were met. All continuous variables in the study were centered at the 2-level group means, and binary variables were coded as 0 and 1 (Raudenbush \& Bryk, 2002). Pearson correlation tests were conducted between main and control variables included in the model. Results indicated that all correlations were less than 0.7 (see Table 1).

----- Insert Table 1 here -----

The data collected in this study were hierarchically structured by 14 therapists and the two treatment conditions. However, the intraclass correlation (ICC) score for therapists was 0.00003 (total variance $=4.1821$; between-group variance $=.0001)$; this indicated that despite multiple therapists' providing treatment; there was no substantial effect by therapists on adolescent therapeutic alliance. There was, however, a significant random effect of treatment type on alliance (ICC $=0.33$; see Table 3). Therefore, we tested our hypotheses through a 2-level regression model accounting for the effect of treatment type on alliance in session 4. Adolescents were designated as level-one and treatment type as level-two. We utilized 'nlme' package in R software (ver3.2.2) to conduct hierarchical linear modeling (HLM; Raudenbush \& Bryk, 2002).

\section{Results}

\section{Preliminary Analysis}

Descriptive Analyses. The sample consisted of 115 adolescent participants; 94 young women (81.7\%) and 21 young men (18.3\%). They were between the ages of 12 and $18(M=$ $14.94, S D=1.68)$. Most of the sample self-identified as ethnic minority (68.7\%) and 
heterosexual (71.3\%). Participants were 48.8\% African American, 28.7\% White, 9.3\%

multiracial, 1.6\% American Indian/ Alaskan Native/ Native Hawaiian/ Pacific Islander, 2.3 Asian, and 6.9\% other. They were largely non-Hispanic/ Latino (74.5\%). The participants reported diverse family relationships that were fairly balanced between those who lived in two-parent families ( $n=31 ; 27 \%$ ), single-parent families ( $n=30 ; 26 \%$ ), and two-parent blended families ( $n$ $=17 ; 15 \%)$. Less than half (40\%) of their households had incomes less than the Gross Domestic Product per capita in the United States in 2015 (\$51,486).

The mean score of adolescent depression was $30.19(S D=7.89)$, and the mean score of suicidal ideation was $49.70(S D=14.98)$. There was slight change in the mean alliance score from $3.77(S D=3.77)$ at the first session to $4.23(S D=4.23)$ at the fourth session. Mean scores of attachment avoidance and anxiety with a mother (M-C avoidant score = 3.63; M-C anxiety score $=2.57)$ and father $(\mathrm{F}-\mathrm{C}$ avoidant score $=4.60 ; \mathrm{F}-\mathrm{C}$ anxious score $=3.38)$ were calculated . Sample descriptive information is provided in Table 2.

----- Insert Table 2 here -----

Null Model. For our nested data within treatment-type, the unconditional variance components model for adolescents was first tested as null model in HLM. The result indicated that between-treatment variance was 1.95 and individual-level variance was 3.94 (see Table 3). That is, $67 \%$ of variation was found at the adolescent level (level 1) and 33\% of the variation lies between treatment types (level 2) as our ICC score was reported in the previous section. The random effect of treatment types on therapeutic alliance was significant as shown in significant F-value (see Table 3) $(F=221.42)$. Specifically, FE-NST showed greater alliance at session 4 than the ABFT condition. Thus, it necessitated multilevel modeling in our study to account for the effect of treatment type as a level-2 between subjects variable. 
----- Insert Table 3 here -----

Evaluating model fit. The Akaike Information Criterion (AIC) and number of parameters for the models were examined to seek the better-fitting model. AIC of the unconditional variance component model was 649.95. When only four main variables were included in the model, AIC was 650.86. When nine covariates were added, AIC became 647.66 dropping by 3.2. Therefore, the final model which included both main and control variables provided a better fit for the data than the model with four main variables alone.

\section{Full Model}

Random effects. First, random effects by treatment conditions were investigated. The results exposed that the group random effect of treatment type explained $35 \%$ of variance in therapeutic alliance in our final model (See Table 4). It also revealed that there was no decrease in random effect of treatment-type at the final model in comparison to the null model, implying that added variables at the final model were more likely to account for the individual-level variance as compared to group-level (treatment type) variance. Specifically, covariates added in the main model explain $6.15 \%$ of between-treatment type variance and $15.22 \%$ of adolescent variance in therapeutic alliance. Thus, covariates included in the model have explanatory power, particularly at an individual level.

----- Insert Table 4 here -----

Main effects. There was a significant main effect in predicting early therapeutic alliance. Adolescents' avoidant attachment to a mother at baseline negatively predicted therapeutic alliance at session four ( $\beta=-0.49, p<.05$; see Table 4$)$. Therefore, adolescents who reported stronger avoidant attachment to their mother reported lower therapeutic alliance, after controlling for impressions of the therapist at session one, adolescents' gender, race, age, depression, 
suicidal ideation, paternal proximity, family income, and father's presence in the therapy session. Among the covariates, impressions of the therapist at session one was the only significant predictor of early alliance $(\beta=0.46, p<.01$; see Table 4$)$.

\section{Discussion}

Decades of research has indicated that a strong therapeutic alliance contributes to better treatment outcomes for children, adolescents, and adults. Few studies have examined client and relational characteristics that contribute to early alliance in youth populations (Baylis et al., 2011; Shirk et al., 2011). This study focused on the unique contributions of perceived attachment to mothers and fathers on early alliance, while controlling for client demographics, symptom severity, treatment type, and initial impressions of the therapeutic relationship. Our research pointed to an association between perceived attachment insecurity in adolescents and therapeutic alliance in both the individual and family intervention models. Specifically, those adolescents who reported more insecurity with their mothers were less likely to build a strong therapeutic alliance. This remained true even while controlling for demographic factors and symptom severity. These findings suggest that adolescents' interpersonal schemas may have more to do with developing a therapeutic relationship than demographic or psychiatric characteristics.

Our findings concur with other studies demonstrating associations between greater parental attachment avoidance, higher internalizing symptoms, and lower levels of alliance (Brenning, Soenens, Braet, \& Bal, 2012). Indeed, adult studies have also found that secure attachment to mothers is associated with greater therapeutic alliance (Mallinckrodt, Gantt, \& Coble, 1995; Mikulincer \& Shaver, 2008). Avoidant attachment to mothers has also been associated with other treatment factors for adolescents. For example, Byrd, Patterson, and Turchik (2010) found that avoidant attachment was associated with psychotherapy outcome, with 
therapeutic alliance being an essential mediator. In addition, Tasca, Taylor, Ritchie, and Balfour (2004) found that attachment avoidance with mothers was related to treatment dropout.

Attachment avoidance with mothers has also been consistently linked to mental health concerns, such as increased incidence of eating disorders in adolescent girls, externalizing disorders in adolescent boys, and increased substance misuse across genders (Barrowclough et al., 2010; Koskina \& Giovazolias., 2010; Tereno et al., 2008). Thus, avoidance with mothers seems to impact individual and relational factors related to psychotherapy process and outcome.

The same was not true for adolescents reporting attachment anxiety with their mothers in our study. This finding is contrary to some existing literature showing a high correlation between greater attachment anxiety and working alliance (e.g., Daly \& Mallinckrodt, 2009; Marmarosh et al., 2009; Mikulincer \& Shaver, 2008). We also did not find that adolescents’ attachment to fathers was predictive of early therapeutic alliance. Some prior studies have shown associations between attachment to fathers and therapeutic alliance (e.g., Mikulincer et al., 2013; Duchesne \& Ratelle, 2014). Our null findings may be attributable to our participants’ characteristics; they were from predominantly single-mother families or blended families with an absent father. It may be possible that youth in these families were more impacted by their mothers and other caregivers present in their lives as opposed to those who were absent.

An early impression of the therapist was the only control variable that added significant variance to the final model. That is, those adolescents who reported a positive impression of the therapist at the end of the first session were also likely to report a stronger alliance at session four. Prior studies have suggested that clients’ innate relational capacity and pre-existing expectations about therapy may inform alliance formation (Arnow \& Steidtmann, 2014; Horvath, Marx, \& Woudzia, 1991). This is consistent with attachment theory in that clients’ internal 
working models of relational expectations influence their initial impressions of therapy and their capacity to develop a therapeutic relationship.

Although not a focus of this study, we found a significant role of treatment type, as a random effect, predicting working alliance. Participants in FE-NST reported greater therapeutic alliance scores than in ABFT. This could be due to the focus of supportive individual therapy that follows the client's lead with empathy and positive regard. In contrast, in family therapy, the therapist must make and maintain a bond with multiple people simultaneously. In addition, an ABFT therapist is changing relational structures and addressing attachment injuries with caregivers, a much more challenging and uncomfortable therapeutic agenda. Some prior studies show that structured individual therapies are a better environment to build working alliance between a therapist and a client, while others suggest a need for further research in the context of relationally-focused treatments (Constantino et al., 2005; Hogue, Dauber, Stambaugh, Cecero, \& Liddle, 2006; Martin et al., 2000; Raue, Goldfried, \& Barkham, 1997).

In light of these findings, it is worth hypothesizing how attachment avoidance with mothers contributes to a therapeutic alliance. Attachment-related avoidance reflects a person's distrust of the goodwill of others (Bowlby, 1969; 1988; Waters, Crowell, Elliott, Corcoran, \& Trebous, 2002). Adolescents with insecure attachment styles have low expectations of relationships and others' capacity to support them. Perceptions of distrust lead to efforts to maintain emotional independence and distance from others in order to prevent disappointment and abandonment. Avoidant adolescents tend to use deactivating relational strategies, denying their own vulnerability and need for protection and care. In this way, an avoidant style helps to self-regulate emotional proximity by denying attachment needs. Not surprisingly, this relational strategy can prevent adolescents from trusting and relying on a therapist, compromising alliance. 


\section{Limitations \& Future Research}

The present study has several limitations. First, we used the TAQS to assess alliance instead of the more commonly-used Working Alliance Inventory (WAI Horvath \& Greenberg, 1989). This limits our ability to compare our findings to studies that use the WAI. The TAQS, however has been shown to be trans diagnostic and specifically suitable for adolescents. (Riemer et al., 2012). Second, we only used adolescent self-report alliance data. The study would have been strengthened by collecting parent data and observer report data. Finally, the ECR-RS is a measure of attachment style. Measurements of attachment state of mind are better suited to assess the internal working model. Attachment style has been found to be a separate construct than attachment state of mind that captures one's perception of their internalized attachment schemas (Mikulincer, 1995; Waters et al., 2002). Therefore, measures examining attachment state of mind, such as the Adult/Adolescent Attachment Interview (AAI), may offer additional perspectives (Kaplan \& Main, 1996). Despite these limitations, self-report measures of attachment continue to be used extensively and make important contributions to the field.

In this study, we also did not have sufficient data on therapist variables (e.g., years of experience, training, attachment style). Research has shown that a therapist's own attachment style and his/her reflective responses to clients may be associated with therapeutic alliance and managing client resistance (Rubino, Barker, Roth, \& Fearon, 2000; Sauer, Anderson, Gormley, Richmond, \& Preacco, 2010). These therapist factors are worth exploring in future research. Finally, this study explored early therapeutic alliance as a single point in time. We plan to examine trajectories of therapeutic alliance formation through growth curve analysis in future analyses to better understand the development and maintenance of the therapeutic relationship over time. In addition, researchers could explore the moderating role played by attachment 
insecurity in the relationship between therapeutic alliance and client outcomes for clients grouped in either family therapy or individual-focused therapy modalities. Expanding research efforts in these areas may uncover important factors associated with therapeutic alliance development and formation with adolescents.

\section{Clinical Implications}

For depressed adolescents, therapeutic alliance may be complicated by a variety of factors such as developing interpersonal capacities, a growing sense of self, stressful home environments, mandatory treatment). (Shirk et al., 2011). Clinicians can apply therapeutic alliance-building strategies within individual and family contexts when working with avoidant clients (Crits-Cristoph et al., 2006). When appropriate, therapists can consider addressing clients’ possible distrust and resistance to therapy early in treatment. Acknowledging, validating, and exploring this ambivalence might help clients feel less guarded. In these circumstances, the therapist can provide the groundwork for building trust. This technique has been referred to as “creating therapeutic distance” in prior research studies (Bachelor et al., 2010, Byrd et al., 2010; Daly \& Mallinckrodt, 2009)

In addition, when appropriate, therapists might consider addressing adolescents’ disappointments/anger toward their parents about their unavailability and insensitivity. Helping an adolescent who has experienced these relational disappointments and increasing awareness and understanding about the impact they have had on their expectations of future relationships might free them to form new relational schemas and have different expectations and hopes about future relationships (Diamond, Diamond, \& Levy, 2014). With these more resistant adolescents, Bordin's (1979) recommends focusing on three dimensions: bond (i.e., therapeutic relationship), tasks (i.e., specific interventions), and goals (i.e., larger aims of treatment). Research has 
demonstrated that this approach has been successful for building an early alliance with depressed and suicidal adolescents (Myrick, Green \& Crenshaw, 2014).

\section{Conclusion}

Therapeutic alliance continues to be an important area of research and clinical interest. The quality of the relationship between therapists and clients determines treatment outcomes (Horvath et al., 2011; Lambert \& Barley, 2001; Martin et al., 2000) and retention (Wintersteen, Mensinger, \& Diamond, 2005). This relationship can also guide clinicians about the most appropriate treatment approach with a particular client (Martin et al., 2000). This study suggests that, in a sample of depressed and suicidal adolescents, perceived attachment insecurity to mothers’ leads to lower therapeutic alliance. Interventions addressing clients' relational expectations early in treatment might increase alliance formation. This should be explored in future studies. 


\section{References}

Allen, J. P., Hauser, S. T., \& Borman-Spurrell, E. (1996). Attachment theory as a framework for understanding sequelae of severe adolescent psychopathology: An 11-year follow-up study. Journal of Consulting and Clinical Psychology, 64(2), 254-263.

Arnow, B. A., \& Steidtmann, D. (2014). Harnessing the potential of the therapeutic alliance. World Psychiatry, 13(3), 238-240. doi: 10.1002/wps.20147

Bachelor, A., Meunier, G., Laverdiere, O., \& Gamache, D. (2010). Client attachment to therapist: Relation to client personality and symptomatology, and their contributions to the therapeutic alliance. Psychotherapy: Theory, Research, Practice, Training, 47(4), 454-468.

Barber, J. P., Connolly, M. B., Crits-Christoph, P., Gladis, L., \& Siqueland, L. (2000). Alliance predicts patients' outcome beyond in treatment change in symptoms. Journal of Consulting and Clinical Psychology, 68(6), 1027-1032. doi: 10.1037/0022006X.68.6.1027

Barrowclough, C., Meier, P., Beardmore, R., \& Emsley, R. (2010). Predicting therapeutic alliance in clients with psychosis and substance misuse. The Journal of Nervous and Mental Disease, 198(5), 373-377.

Baylis, P. J., Collins, D., \& Coleman, H. (2011). Child Alliance Process Theory: A qualitative study of a child centred therapeutic alliance. Child and Adolescent Social Work Journal, 28(2), 79-95. doi: 10.1007/s10560-011-0224-2

Beck, A. T., Steer, R. A., \& Brown, G. K. (1996). Manual for the Beck Depression Inventory-II. San Antonio, TX: Psychological Corporation. 
Beck, M., Friedlander, M. L., \& Escudero, V. (2006). Three perspectives on clients' experiences of the therapeutic alliance: A discovery-oriented investigation. Journal of Marital and Family Therapy, 32(3), 355-368.

Bordin, E. S. (1979). The generalizability of the psychoanalytic concept of the working alliance. Psychotherapy: Theory, Research \& Practice, 16(3), 252-260.

Bowlby, J. (1988). Attachment, communication, and the therapeutic process. A secure base: Parent-child attachment and healthy human development, 137-157. Basic books, New York

Bowlby, J. (1969). Attachment and loss: Attachment. New York, NY: Basic Books.

Bowlby, J. (1973). Attachment and loss: Separation (Vol. 2). New York, NY: Basic Books.

Brenning, K., Soenens, B., Braet, C., \& Bal, S. (2012). The role of parenting and motheradolescent attachment in the intergenerational similarity of internalizing symptoms. Journal of Youth and Adolescence, 41(6), 802-816.

Brent, D. A., \& Kolko, D. J. (1991). Supportive relationship treatment manual (NST) (non directive therapy). Pittsburgh, PA: University of Pittsburgh. Unpublished manual.

Bretherton, I., \& Munholland, K. A. (2008). Internal working models in attachment relationships: Elaborating a central construct in attachment theory. In J. Cassidy \& P. R. Shaver (Eds.), Handbook of attachment: Theory, research, and clinical applications(pp. 102-127). New York: Guilford Press

Byrd, K. R., Patterson, C. L., \& Turchik, J. A. (2010). Working alliance as a mediator of client attachment dimensions and psychotherapy outcome. Psychotherapy: Theory, Research, Practice, Training, 47(4), 631-636. http://doi.org/10.1037/a0022080 
Castro-Blanco, D. E., \& Karver, M. S. (2010). Elusive alliance: Treatment engagement strategies with high-risk adolescents. American Psychological Association.

Clark, S. E., \& Symons, D. K. (2009). Representations of attachment relationships, the self, and significant others in middle childhood. Journal of the Canadian Academy of Child and Adolescent Psychiatry, 18(4), 316-321.

Constantino, M. J., Arnow, B. A., Blasey, C., \& Agras, W. S. (2005). The association between patient characteristics and the therapeutic alliance in cognitive-behavioral and interpersonal therapy for bulimia nervosa. Journal of Consulting and Clinical Psychology, 73(2), 203-211.

Crits-Christoph, P., Gibbons, M. B. C., Crits-Christoph, K., Narducci, J., Schamberger, M., \& Gallop, R. (2006). Can therapists be trained to improve their alliances? A preliminary study of alliance-fostering psychotherapy. Psychotherapy Research, 16(3), 268-281.

Daly, K. D., \& Mallinckrodt, B. (2009). Experienced therapists’ approach to psychotherapy for adults with attachment avoidance or attachment anxiety. Journal of Counseling Psychology, 56(4), 549.

De Haan, A. M., Boon, A. E., de Jong, J. T., Hoeve, M., \& Vermeiren, R. R. (2013). A metaanalytic review on treatment dropout in child and adolescent outpatient mental health care. Clinical Psychology Review, 33(5), 698-711.

De Winter, S., Bosmans, G., \& Salemink, E. (2017). Exploring the causal effect of interpretation bias on attachment expectations. Child Development, 88(1), 131-140. doi:10.1111/cdev.12587

Diamond, G. S., Diamond, G. M., \& Levy, S. A. (2014). Attachment Based Family Therapy for depressed adolescents. Washington D.C: American Psychological Association. 
Diamond, G. M., Liddle, H. A., Hogue, A., \& Dakof, G. A. (1999). Alliance-building interventions with adolescents in family therapy: A process study. Psychotherapy: Theory, Research, Practice, Training, 36(4), 355-372

Diener, M. J., \& Monroe, J. M. (2011). The relationship between adult attachment style and therapeutic alliance in individual psychotherapy: A meta-analytic review. Psychotherapy, 48(3), 237-248.

DiGiuseppe, R., Linscott, J., \& Jilton, R. (1996). Developing the therapeutic alliance in childadolescent psychotherapy. Applied and Preventive Psychology, 5(2), 85-100. doi: $10.1016 / \mathrm{S} 0962-1849(96) 80002-3$

Duchesne, S., \& Ratelle, C. F. (2014). Attachment security to mothers and fathers and the developmental trajectories of depressive symptoms in adolescence: Which parent for which trajectory? Journal of Youth and Adolescence, 43(4), 641-654. doi: 10.1007/s10964-013-0029-z

Eliot, A. O. (2009). Adolescent alliance building: A contemporary approach to an ancient concept. Annals of the American Psychotherapy Association, 12(3), 10-16.

Fjermestad, K. W., McLeod, B. D., Heiervang, E. R., Havik, O. E., Öst, L. G., \& Haugland, B. S. (2012). Factor structure and validity of the therapy process observational coding system for Child Psychotherapy-Alliance Scale. Journal of Clinical Child \& Adolescent Psychology, 41(2), 246-254.

Fraley, R. C., Heffernan, M. E., Vicary, A. M., \& Brumbaugh, C. C. (2011). The experiences in close relationships—Relationship Structures Questionnaire: A method for assessing attachment orientations across relationships. Psychological Assessment, 23(3), 615-625. 
Galdiolo, S., \& Roskam, I. (2016). From me to us: The construction of family alliance. Infant Mental Health Journal, 37(1), 29-44.

Green, J. (2006). The therapeutic alliance-a significant but neglected variable in child mental health treatment studies. Journal of Child Psychology and Psychiatry, 47(5), 425-435.

Hawks, J. M. (2015). Exploring the therapeutic alliance with adolescents and their caregivers: A qualitative approach. Theses and Dissertations--Family Sciences. 32. http://uknowledge.uky.edu/hes_etds/32

Hawley, K. M., \& Garland, A. F. (2008). Working alliance in adolescent outpatient therapy: Youth, parent and therapist reports and associations with therapy outcomes. Child \& Youth Care Forum, 37(2), 59-74. doi: 10.1007/s10566-008-9050-x

Hogue, A., Dauber, S., Stambaugh, L. F., Cecero, J. J., \& Liddle, H. A. (2006). Early therapeutic alliance and treatment outcome in individual and family therapy for adolescent behavior problems. Journal of Consulting and Clinical Psychology, 74(1), 121-129.

Horvath, A. O. (2000). The therapeutic relationship: From transference to alliance. Journal of Clinical Psychology, 56(2), 163-173. doi: 10.1002/(SICI)10974679(200002)56:2<163::AID-JCLP3>3.0.CO;2-D

Horvath, A. O., Del Re, A. C., Flückiger, C., \& Symonds, D. (2011). Alliance in individual psychotherapy. Psychotherapy, 48(1), 9-16. doi: 10.1037/a0022186

Horvath, A. O., \& Greenberg, L. S. (1989). Development and validation of the Working Alliance Inventory. Journal of Counseling Psychology, 36(2), 223-233.

Horvath, A. O., Marx, R. W., \& Woudzia, J. (1991). Development and preliminary validation of the Counselors' Intentions List. Psychological Assessment: A Journal of Consulting and Clinical Psychology, 3(3), 469-477. 
Johnson, L. N., Ketring, S. A., Rohacs, J., \& Brewer, A. L. (2006). Attachment and the therapeutic alliance in family therapy. The American Journal of Family Therapy, 34(3), 205-218. doi: 10.1080/01926180500358022

Kaplan, N., \& Main, M. (1996). Adult attachment interview. Unpublished manuscript, The Authors, Berkeley CA

.Kobak, R., \& Zajac, K. (2011). Rethinking adolescent states of mind: A relationship/lifespan view of attachment and psychopathology. In D. Cicchetti \& G. I. Roisman (Eds.), Minnesota Symposia on Child Psychology, Volume 36: The Origins and Organization of Adaptation and Maladaptation (pp. 185-229 Hoboken, NJ: Wiley.

Kobak, R., Zajac, K., Madsen, S. (2016) Disruptions in Attachment Bonds: Theory, Assessment and Reparative Processes. Handbook of Attachment: Theory, Research and Clinical Implications, (Cassidy \& Shaver, Eds.), New York: Guilford Press (pp. 25-39).

Karver, M. S., Handelsman, J. B., Fields, S., \& Bickman, L. (2006). Meta-analysis of therapeutic relationship variables in youth and family therapy: The evidence for different relationship variables in the child and adolescent treatment outcome literature. Clinical Psychology Review, 26(1), 50-65.

Kazdin, A. E. (2005). Evidence-based assessment for children and adolescents: Issues in measurement development and clinical application. Journal of Clinical Child \& Adolescent Psychology, 34(3), 548-558. doi: 10.1207/s15374424jccp3403_10

Koskina, N., \& Giovazolias, T. (2010). The effect of attachment insecurity in the development of eating disturbances across gender: The role of body dissatisfaction. The Journal of Psychology, 144(5), 449-471. 
Krupnick, J. L., Sotsky, S. M., Simmens,S., Moyer, J., Elkin, I., Watkins, J., \& Pilkonis, P.A. (1996). The role of the therapeutic alliance in psychotherapy \& pharmacotherapy outcome: Findings in the National Institute of Mental Health Treatment of Depression Collaborative Research Program. Journal of Consulting and Clinical Psychology, 64(3), 532-539.

Lambert, M. J., \& Barley, D. E. (2001). Research summary on the therapeutic relationship and psychotherapy outcome. Psychotherapy, 38(4), 357-361. doi: 10.1037/00333204.38.4.357

Levin, L., Henderson, H. A., \& Ehrenreich-May, J. (2012). Interpersonal predictors of early therapeutic alliance in a transdiagnostic cognitive-behavioral treatment for adolescents with anxiety and depression. Psychotherapy, 49(2), 218-230. doi: 10.1037/a0028265

Lindgren, A., Barber, J. P., \& Sandahl, C. (2008). Alliance to the group-as-a-whole as a predictor of outcome in Psychodynamic Group Therapy. International Journal of Group Psychotherapy, 58(2), 163-184.

Maier, M., Bernier, A., Pekrun, R., Zimmermann, P., \& Grossmann, K. (2004). Attachment working models as unconscious structures: An experimental test. International Journal of Behavioral Development, 28(2), 180-189.

Mallinckrodt, B., Gantt, D. L., \& Coble, H. M. (1995). Attachment patterns in the psychotherapy relationship: Development of the Client Attachment to Therapist Scale. Journal of Counseling Psychology, 42(3), 307-307.

Marmarosh, C. L., Gelso, C. J., Markin, R. D., Majors, R., Mallery, C., \& Choi, J. (2009). The real relationship in psychotherapy: Relationships to adult attachments, working alliance, transference, and therapy outcome. Journal of Counseling Psychology, 56(3), 337-350. 
Martin, D. J., Garske, J. P., \& Davis, M. K. (2000). Relation of the therapeutic alliance with outcome and other variables: A meta-analytic review. Journal of Consulting and Clinical Psychology, 68(3), 438-450. doi: 10.1037/0022-006X.68.3.438

McLeod, B. D. (2011). Relation of the alliance with outcomes in youth psychotherapy: A metaanalysis. Clinical Psychology Review, 31(4), 603-616.

Mikulincer, M. (1995). Attachment style and the mental representation of the self. Journal of Personality and Social Psychology, 69(6), 1203-1215.

Mikulincer, M., \& Shaver, P. R. (2008). Adult attachment and affect regulation. In J. Cassidy \& P. R. Shaver (Eds.), Handbook of attachment: Theory, research, and clinical applications (pp. 503-531). New York, NY: Guilford Press.

Mikulincer, M., Shaver, P. R., \& Berant, E. (2013). An attachment perspective on therapeutic processes and outcomes. Journal of Personality, 81(6), 606-616.

Muehlenkamp, J. J. (2006). Empirically supported treatments and general therapy guidelines for non-suicidal self-injury. Journal of Mental Health Counseling, 28(2), 166-185.

Myrick, A. C., Green, E. J., \& Crenshaw, D. (2014). The influence of divergent parental attachment styles on adolescent maturation implications for family counseling practitioners. The Family Journal, 22(1), 35-42.

Raudenbush, S. W., \& Bryk, A. S. (2002). Hierarchical linear models: Applications and data analysis methods ( $2^{\text {nd }}$ ed.). Newbury Park, CA: Sage.

Raue, P. J., Goldfried, M. R., \& Barkham, M. (1997). The therapeutic alliance in psychodynamic-interpersonal and cognitive-behavioral therapy. Journal of Consulting and Clinical Psychology, 65(4), 582-587. 
Reynolds, W. M., \& Mazza, J. J. (1999). Assessment of suicidal ideation in inner-city children and young adolescents: Reliability and validity of the Suicidal Ideation QuestionnaireJR. School Psychology Review, 28(1), 17-30.

Riemer, M., Athay, M. M., Bickman, L., Breda, C., Kelley, S. D., \& De Andrade, A. R. V. (2012). The Peabody Treatment Progress Battery: History and methods for developing a comprehensive measurement battery for youth mental health. Administration and Policy in Mental Health and Mental Health Services Research, 39(1-2), 3-12.

Rogers, C. R. (1977). Carl Rogers on personal power. New York, NY: Delacorte Press.

Roth, P. L. (1994). Missing data: A conceptual review for applied psychologists. Personnel Psychology, 47(3), 537-560.

Rubino, G., Barker, C., Roth, T., \& Fearon, P. (2000). Therapist empathy and depth of interpretation in response to potential alliance ruptures: The role of therapist and patient attachment styles. Psychotherapy Research, 10(4), 408-420.

Safran, J. D., \& Muran, J. C. (2000). Resolving therapeutic alliance ruptures: Diversity and integration. Journal of Clinical Psychology, 56(2), 233-243. doi: 10.1002/(SICI)10974679(200002)56:2<233::AID-JCLP9>3.0.CO;2-3

Sauer, E. M., Anderson, M. Z., Gormley, B., Richmond, C. J., \& Preacco, L. (2010). Client attachment orientations, working alliances, and responses to therapy: A psychology training clinic study. Psychotherapy Research, 20(6), 702-711.

Schlomer, G. L., Bauman, S., \& Card, N. A. (2010). Best practices for missing data management in counseling psychology. Journal of Counseling Psychology, 57(1), 1-10.

Sexton, H., Littauer, H., Sexton, A., \& Tømmerås, E. (2005). Building an alliance: Early therapy process and the client-therapist connection. Psychotherapy Research, 15(1-2), 103-116. 
Shirk, S. R., Gudmundsen, G., Kaplinski, H. C., \& McMakin, D. L. (2008). Alliance and outcome in cognitive-behavioral therapy for adolescent depression. Journal of Clinical Child \& Adolescent Psychology, 37(3), 631-639.

Shirk, S. R., Karver, M. S., \& Brown, R. (2011). The alliance in child and adolescent psychotherapy. Psychotherapy, 48(1), 17-24. doi: 10.1037/a0022181

Shomaker, L. B., \& Furman, W. (2009). Parent-adolescent relationship qualities, internal working models, and attachment styles as predictors of adolescents' interactions with friends. Journal of Social and Personal Relationships, 26(5), 579-603.

Spoth, R., Redmond, C., Hockaday, C., \& Shin, C. Y. (1996). Barriers to participation in family skills preventive interventions and their evaluations: A replication and extension. Family Relations, 45 (3), 247-254.

Strauss, J. L., Hayes, A. M., Johnson, S. L., Newman, C. F., Brown, G. K., Barber, J. P., ... \& Beck, A. T. (2006). Early alliance, alliance ruptures, and symptom change in a nonrandomized trial of cognitive therapy for avoidant and obsessive-compulsive personality disorders. Journal of Consulting and Clinical Psychology, 74(2), 337-345.

Tasca, G. A., Taylor, D., Ritchie, K., \& Balfour, L. (2004). Attachment predicts treatment completion in an eating disorders partial hospital program among women with anorexia nervosa. Journal of Personality Assessment, 83(3), 201-212.

Tereno, S., Soares, I., Martins, C., Celani, M., \& Sampaio, D. (2008). Attachment styles, memories of parental rearing and therapeutic bond: A study with eating disordered patients, their parents and therapists. European Eating Disorders Review, 16(1), 49-58. 
Thompson, S. J., Bender, K., Lantry, J., \& Flynn, P. M. (2007). Treatment engagement: Building therapeutic alliance in home-based treatment with adolescents and their families. Contemporary Family Therapy, 29(1-2), 39-55.

Waters, E., Crowell, J., Elliott, M., Corcoran, D., \& Treboux, D. (2002). Bowlby's secure base theory and the social/personality psychology of attachment styles: Work (s) in progress. Attachment \& Human Development, 4(2), 230-242.

Waters, E., Merrick, S., Treboux, D., Crowell, J., \& Albersheim, L. (2000). Attachment security in infancy and early adulthood: A twenty-year longitudinal study. Child Development, 71(3), 684-689.

Wampold, B. E. (2001). The great psychotherapy debate. Mahwah, NJ: Erlbaum.

Wintersteen, M. B., Mensinger, J. L., \& Diamond, G. S. (2005). Do gender and racial differences between patient and therapist affect therapeutic alliance and treatment retention in adolescents? Professional Psychology: Research and Practice, 36(4), 400-408. doi: 10.1037/0735-7028.36.4.400

Zack, S. E., Castonguay, L. G., Boswell, J. F., McAleavey, A. A., Adelman, R., Kraus, D. R., \& Pate, G. A. (2015). Attachment history as a moderator of the alliance outcome relationship in adolescents. Psychotherapy, 52(2), 258-267. 
Table 1. Bivariate Correlations between Main Variables and Covariates in the Model

\begin{tabular}{|c|c|c|c|c|c|c|c|c|c|c|c|c|c|c|c|c|}
\hline & & 1 & 2 & 3 & 4 & 5 & 6 & 7 & 8 & 9 & 10 & 11 & 12 & 13 & 14 & 15 \\
\hline 1 & Early Alliance & - & -.079 & -.166 & $-.253^{* *}$ & -.169 & .000 & -.154 & $\begin{array}{c}.527 * \\
*\end{array}$ & -.057 & -.160 & -.130 & -.090 & -.155 & -.065 & $-.348^{* *}$ \\
\hline 2 & $\begin{array}{l}\text { MC Avoidant } \\
\text { Attachment }\end{array}$ & & - & $.421^{* *}$ & $.302 * *$ & $.253 * *$ & -.007 & .071 & -.073 & .088 & -.170 & -.047 & -.020 & -.127 & $-.203^{*}$ & .103 \\
\hline 3 & $\begin{array}{l}\text { MC Anxious } \\
\text { Attachment }\end{array}$ & & & - & .110 & $.447 * *$ & .130 & $.225^{*}$ & -.109 & .013 & -.051 & -.014 & -.072 & -.102 & $-.201^{*}$ & .031 \\
\hline 4 & $\begin{array}{l}\text { FC Avoidant } \\
\text { Attachment }\end{array}$ & & & & - & $.536 * *$ & .099 & .128 & -.092 & -.080 & $-.194 *$ & -.148 & -.024 & -.053 & -.043 & .063 \\
\hline 5 & $\begin{array}{l}\text { FC Anxious } \\
\text { Attachment }\end{array}$ & & & & & - & $.223^{*}$ & .177 & -.112 & -.095 & $-.243^{* *}$ & $-.244^{* *}$ & -.121 & $-.194 *$ & $-.249 *$ & -.011 \\
\hline 6 & $\begin{array}{l}\text { Suicidal } \\
\text { Ideation }\end{array}$ & & & & & & - & $.378^{* *}$ & .010 & -.010 & -.095 & -.132 & .070 & -.043 & -.077 & .006 \\
\hline 7 & Depression & & & & & & & - & -.183 & -.183 & .035 & -.026 & $.238 *$ & .129 & -.116 & .019 \\
\hline 8 & $\begin{array}{l}\text { Initial } \\
\text { Impression of } \\
\text { Therapist }\end{array}$ & & & & & & & & - & -.082 & -.181 & .012 & -.073 & -.032 & .079 & $-.202 *$ \\
\hline 9 & $\begin{array}{l}\text { Gender of } \\
\text { Adolescents } \\
\text { (Male) }\end{array}$ & & & & & & & & & - & -.016 & .028 & -.052 & -.076 & -.015 & .043 \\
\hline $\begin{array}{l}1 \\
0\end{array}$ & $\begin{array}{l}\text { Father } \\
\text { Proximity }\end{array}$ & & & & & & & & & & - & $.421 * *$ & -.043 & $.394 * *$ & $.255^{* *}$ & .096 \\
\hline $\begin{array}{l}1 \\
1\end{array}$ & $\begin{array}{l}\text { Father's } \\
\text { Presence at } \\
\text { Therapy }\end{array}$ & & & & & & & & & & & - & -.144 & $.291 * *$ & $.333^{* *}$ & .178 \\
\hline $\begin{array}{l}1 \\
2\end{array}$ & $\begin{array}{l}\text { Age of } \\
\text { Adolescents }\end{array}$ & & & & & & & & & & & & - & .110 & -.042 & -.022 \\
\hline $\begin{array}{l}1 \\
3\end{array}$ & $\begin{array}{l}\text { Race of } \\
\text { Adolescents } \\
\text { (White) }\end{array}$ & & & & & & & & & & & & & - & $.422^{* *}$ & .067 \\
\hline $\begin{array}{l}1 \\
4\end{array}$ & $\begin{array}{l}\text { Family } \\
\text { Income to } \\
\text { Needs }\end{array}$ & & & & & & & & & & & & & & - & .081 \\
\hline $\begin{array}{l}1 \\
5\end{array}$ & $\begin{array}{l}\text { Treatment } \\
\text { Type (ABFT) }\end{array}$ & & & & & & & & & & & & & & & - \\
\hline
\end{tabular}


Table 2. Description of Participants' Characteristics

\begin{tabular}{|c|c|c|c|c|}
\hline & $\mathrm{N}$ & Percent (\%) & Mean & S.D. \\
\hline \multicolumn{5}{|l|}{ Demographics } \\
\hline Age of Adolescents & 115 & & 14.94 & 1.68 \\
\hline \multicolumn{5}{|l|}{ Family Income to Needs Ratio } \\
\hline Categorical Variables & 115 & & 2.08 & 1.43 \\
\hline \multicolumn{5}{|l|}{ Adolescent Gender } \\
\hline Male & 21 & 18.3 & & \\
\hline Female & 94 & 81.7 & & \\
\hline \multicolumn{5}{|l|}{ Adolescent Race } \\
\hline Non-White & 79 & 68.7 & & \\
\hline White & 36 & 31.3 & & \\
\hline \multicolumn{5}{|l|}{ Father Proximity } \\
\hline Rarely Seen & 40 & 34.8 & & \\
\hline Often & 24 & 20.9 & & \\
\hline Everyday & 49 & 42.6 & & \\
\hline \multicolumn{5}{|l|}{ Father's Presence in the Therapy } \\
\hline Yes & 46 & 40.0 & & \\
\hline No & 69 & 60.0 & & \\
\hline \multicolumn{5}{|l|}{ Treatment Type } \\
\hline ABFT & 60 & 52.2 & & \\
\hline NST & 55 & 47.8 & & \\
\hline \multicolumn{5}{|l|}{ Symptom Severity } \\
\hline Suicidal Ideation (SIQ) Score & 115 & & 49.70 & 14.98 \\
\hline Depression (BDI) Score & 115 & & 30.19 & 7.89 \\
\hline \multicolumn{5}{|l|}{ Alliance } \\
\hline $\begin{array}{l}\text { Initial Impression of Therapist } \\
\text { Alliance }\end{array}$ & 115 & & 20.79 & 3.77 \\
\hline Early Alliance & 112 & & 21.31 & 4.23 \\
\hline \multicolumn{5}{|l|}{ Attachment } \\
\hline M-C Avoidant Attachment & 115 & & 3.63 & 1.50 \\
\hline M-C Anxious Attachment & 115 & & 2.57 & 1.56 \\
\hline F-C Avoidant Attachment & 114 & & 4.60 & 1.81 \\
\hline F-C Anxious Attachment & 114 & & 3.38 & 1.94 \\
\hline
\end{tabular}


Table 3. Parameter Estimates for Null Model

\begin{tabular}{lccccc}
\hline Parameter & $\begin{array}{c}\text { Variance } \\
\text { Component }\end{array}$ & numDF & denDF & $F$-value & $p$-value \\
\hline AIC: 649.95 & & 1 & 113 & 221.42 & $<.0001$ \\
& & & & & \\
Estimates of Covariance Parameters & 3.94 & & & & \\
$\quad$ Residual & & & & & \\
$\quad \begin{array}{l}\text { Intercept Variance (subject= } \\
\text { Treatment Types) }\end{array}$ & 1.95 & & & \\
\hline
\end{tabular}

a. Dependent Variable: Alliance at Session 4

Note. NumDF is a numerator degree of freedom; denDF is a denominator degree of freedom

Table 4. Parameter Estimates for Multilevel Regression Model

\begin{tabular}{|c|c|c|c|c|c|}
\hline Parameter & Coefficient & $S E$ & Df & $t$-value & $p$-value \\
\hline \multicolumn{6}{|l|}{ AIC: 647.66} \\
\hline \multicolumn{6}{|l|}{ Estimates of Fixed effects ${ }^{a}$} \\
\hline Intercept & 21.95 & 1.38 & 100 & 15.82 & 0.00 \\
\hline M-C Avoidant Attachment* & -0.49 & 0.21 & 100 & -2.30 & 0.02 \\
\hline M-C Anxious Attachment & -0.10 & 0.21 & 100 & -0.50 & 0.61 \\
\hline F-C Avoidant Attachment & -0.34 & 0.21 & 100 & -1.56 & 0.12 \\
\hline F-C Anxious Attachment & 0.05 & 0.18 & 100 & 4.23 & 0.76 \\
\hline Initial Impression of Therapist** & 0.46 & 0.11 & 100 & 0.30 & 0.001 \\
\hline Suicidal Ideation & -0.04 & 0.03 & 100 & -1.38 & 0.07 \\
\hline Depression & 0.04 & 0.05 & 100 & 0.82 & 0.41 \\
\hline Gender (Male) & -0.48 & 0.83 & 100 & -0.57 & 0.56 \\
\hline Race (White) & -1.28 & 0.75 & 100 & -1.68 & 0.09 \\
\hline Age & 0.03 & 0.14 & 100 & 0.23 & 0.81 \\
\hline Family Income & 0.02 & 0.03 & 100 & 0.93 & 0.35 \\
\hline Paternal Proximity & -1.13 & 0.31 & 100 & -0.41 & 0.67 \\
\hline \multirow[t]{2}{*}{ Father's Presence in Therapy } & -0.54 & 0.75 & 100 & -4.71 & 0.47 \\
\hline & Variance Component & numDF & denDF & $F$-value & $p$-value \\
\hline \multicolumn{6}{|c|}{ Estimates of Covariance Parameters ${ }^{\mathrm{a}}$} \\
\hline \multirow{3}{*}{$\begin{array}{l}\text { Residual } \\
\text { Intercept Variance (subject } \\
=\text { Treatment Types) }\end{array}$} & & 1 & 100 & 254.46 & $<.0001$ \\
\hline & 3.34 & & & & \\
\hline & 1.83 & & & & \\
\hline
\end{tabular}

a. Dependent Variable: Alliance at Session 4

Note. NumDF is a numerator degree of freedom; denDF is a denominator degree of freedom $* p<.05, * * p<.01, * * * p<.001$ 